\title{
A robótica educacional e as tecnologias da informação e comunicação na construção de conhecimentos substantivos em ciências naturais
}

\author{
the educational robotics and the information and communication technology in \\ substantive construction of knowledge in Natural Sciences
}

\author{
Renati Fronza Chitolina*1 e Neusa Maria John Scheid ${ }^{2}$ \\ ${ }^{1}$ Mestre,Docente da Sociedade Educacional Três de Maio (SETREM), RS, Brasil \\ ${ }^{2}$ Doutora, Docente dos Programas de Pós Graduação em Educação e em Ensino Científico e Tecnológico da \\ Universidade Regional Integrada do Alto Uruguai e das Missões., RS, Brasil
}

\begin{abstract}
Resumo
A evolução da sociedade na utilização intensiva de Tecnologias da Informação e da Comunicação (TIC) questiona os paradigmas de ensino e aprendizagem tradicionais. No presente artigo, relata-se um projeto que teve como objetivo investigar a contribuição do uso do LEGO educacional, integrado as ferramentas das TIC, em especial, os recursos da Web 2.0, na promoção de aprendizagem significativa e construção de conhecimentos substantivos em Ciências Naturais. O desenvolvimento do projeto ocorreu em 2012/2013, com estudantes do Ensino Fundamental de uma escola básica, tendo como marco teórico o Construcionismo de Papert. A análise dos resultados permitiu concluir que o desenvolvimento desse trabalho interdisciplinar, que possibilitou a projeção, montagem e programação de robôs e divulgação do trabalho realizado por meio da criação de uma revista digital, sinaliza para a eficácia educativa do uso das diferentes TIC e da robótica como ferramentas educacionais nas escolas. Para que isso seja possível, torna-se necessária a instrumentalização dos professores e a criação de espaços/tempos para que este trabalho possa ser desenvolvido.
\end{abstract}

Palavras-chave: Robótica educacional. Tecnologias da Informação e da Comunicação. Web 2.0. Construcionismo.

\begin{abstract}
The evolution of society in the intensive use of Information Technology and Communication (ICT) challenges the traditional paradigms of teaching and learning. In this article, we report a project that aimed to investigate the contribution of the use of educational LEGO, integrating ICT tools, in particular, Web 2.0 resources, in promoting meaningful learning and building substantial knowledge in Natural Sciences. The development of the project took place in 2012/2013, with elementary school students of a basic school, with the theoretical framework of Papert's constructionism. The analysis concluded that the development of this interdisciplinary work, that enabled the projection assembly and robots and dissemination of the work done through the creation of a digital magazine, signalize for the educational effectiveness of the use of different ICT and robotics as educational tools in schools. To make this possible, it becomes necessary the instrumentation of teachers and the creation of spaces / times so that this work can be developed.
\end{abstract}

Keywords: Educational robotics.bInformation and Communication Technology's. Web 2.0. Constructionism. 


\section{Introdução}

$\mathrm{O}$ $s$ alunos de hoje fazem parte de uma geração de nativos digitais (PRENSKY, 2010; VERAS, 2011) que já nasceu conectada ao computador, internet e dispositivos móveis como os smartphones e tablets e, por isso, o uso de ferramentas que tornem as aulas mais interessantes e o aprendizado mais efetivo tem sido objeto de muitos estudos, uma vez que, "são necessárias abordagens diferenciadas, que criem um espaço de comunicação entre o professor e o aluno." (CASTANHA ; CASTRO, 2010, p. 29).

Há cerca de trinta anos, Seymour Papert lançou a ideia dos computadores pessoais como ferramentas de aprendizagem, destacando a associação desses à Educação e assumindo uma postura construtiva. Em sua concepção, "os computadores podem e devem ser utilizados como instrumentos para trabalhar e pensar, como meios de realizar projetos, como fonte de conceitos para pensar ideias." (PAPERT, 2008, p.158). Assim, denominou de construcionista a abordagem pela qual o aprendiz constrói, por intermédio do computador, o seu próprio conhecimento.

Para Valente (1999), Papert usou o termo construcionista para mostrar um outro nível de construção do conhecimento, que acontece quando o aluno constrói um objeto de seu interesse (uma obra de arte, um relato de experiência, um programa de computador ou até mesmo um robô), o que pode ser ilustrado através do uso da robótica na educação.

A robótica educacional ou robótica pedagógica é caracterizada por ambientes de aprendizagem no qual o aluno pode montar um robô ou sistema robotizado. É uma prática envolvendo hardware e software, na qual a lógica é inerente na montagem e programação de robôs, envolvendo normalmente problemas do mundo real que estimulam o aprendizado de conceitos intuitivos (MORELATO et. al., 2010) e que, segundo Castilho (2008), objetiva desenvolver o raciocínio lógico, a criatividade, a autonomia no aprendizado, a compreensão de conceitos e o conviver em grupo, num ambiente que envolve tecnologia e trabalho manual.

Com o intuito de incentivar o uso desta ferramenta nas escolas, a LEGO® criou um programa educacional chamado LEGO Zoom Education. A robótica educacional com os kits LEGO ${ }^{\circ}$ surgiu em meados de 1980, quando a empresa dinamarquesa de brinquedos LEGO $₫$ firmou uma parceria com o MIT (Massachusetts Institute of Technology), dos Estados Unidos, possibilitando o investimento de tecnologia em seus produtos e criando assim a LEGO® Education. Um dos primeiros resultados desta parceria foi o lançamento de um programa de computador que controla os robôs construídos com as peças LEGO®. Mas, é em 2006, que a LEGO lança o Mindstorms NXT, uma versão mais moderna do brinquedo que permite ao robô ver, ouvir, falar, dançar e até sentir. (LEGO ZOOM, 2012).

A utilização dessa ferramenta permite, como afirma Papert (2008), criar um ambiente de aprendizagem no qual o conhecimento não é simplesmente transmitido, mas, onde o estudante pode interagir com os objetos, desenvolvendo outros conceitos. Ao final do processo, a ênfase não é para o produto, mas para o processo pelo qual atinge os seus objetivos.

Segundo Papert (2008), algumas formas de aprendizagem são rápidas, muito atraentes e gratificantes. Robôs, máquinas autônomas, são meios atrativos que convidam professores e alunos a ensinar/aprender/ descobrir/inventar em processos coletivos, capazes de conectar abstração e mundo concreto (QUINTANILHA, 2008). É possível trabalhar a área da Robótica de forma pedagógica, vindo a somar esforços para tornar a vida escolar mais desafiadora, criativa e preocupada com o processo inclusivo das pessoas.

O presente artigo teve sua origem no desenvolvimento de um trabalho interdisciplinar desenvolvido com a utilização da robótica educacional, mediada por ferramentas da Web 2.0 para a construção de conhecimentos substantivos em Ciências Naturais numa escola de Educação Básica, situada no noroeste do Rio Grande do Sul, na qual uma das autoras é docente. Envolveu alunos de $8^{\circ}$ ano do Ensino Fundamental durante os anos letivos de 2012 e 2013.

Durante o desenvolvimento do projeto, que abrangeu as disciplinas de Ciências Naturais, Informática, Novas Tecnologias, Língua Estrangeira e Língua Portuguesa, os alunos realizaram atividades de pesquisa bibliográfica, projeção, montagem e programação de robôs utilizando o material da LEGO ${ }^{\circ}$ educacional, tratando de assuntos relacionados aos sistemas do corpo humano. Para a divulgação dos resultados do projeto, os estudantes produziram relatórios que foram apresentados para uma banca de professores, utilizando recursos da Web 2.0 como meios interativos (PREZI, infográficos e blogs). A culminância do projeto ocorreu com a criação de uma revista digital, cujo objetivo é divulgar o uso das TIC na construção do conhecimento.

Dessa forma, foi possível avaliar positivamente a utilização do $\mathrm{LEGO}{ }^{\circledR}$, associado às ferramentas da Web 2.0, no ensino de Ciências Naturais.

No Brasil, projetos realizados pela Robótica educacional, conforme Quintanilha (2008), ainda não passam de iniciativas isoladas feitas por centros de pesquisa, principalmente universidades. Falta um olhar que direcione esforços para que robôs possam apoiar o cenário escolar como um meio que insira a informática dentro de outras disciplinas, como a Matemática, a Física, a Biologia dentre outras; possibilitando a realização de trabalhos em grupo e a resolução de problemas no cotidiano escolar, estimulando a criatividade e a participação. 


\section{Aprendizagem centrada no aluno: novos desafios - novos conhecimentos}

Em um cenário de profundas transformações e avanços tecnológicos, é fundamental reconhecer que "vivemos em um tempo de ressignificações e profundas mudanças, onde a escola precisa reconstruir seu sentido educativo por meio de um trabalho que contemple a interdisciplinaridade e a contextualização." (CASTANHA E CASTRO, 2010, p. 37).

Neste contexto, ao perceber que os alunos atuais nasceram com as Tecnologias da Informação e da Comunicação funcionando "a todo o vapor" e que foram criados praticamente dentro das redes sociais, sentindose muito à vontade utilizando ao mesmo tempo rádio, televisão, telefone, música, computadores e internet surgiu um desafio: tornar o trabalho interdisciplinar já existente na escola, mais interessante e próximo da realidade dos alunos.

Durante o planejamento do ano letivo de 2013, decidiu-se por fazer algumas alterações no projeto interdisciplinar que já vinha sendo desenvolvido, inserindo-se mais recursos tecnológicos e redimensionando as atividades da robótica a fim de dar ao aluno mais autonomia no desenvolvimento das atividades propostas e promover a construção do conhecimento de forma colaborativa e compartilhada.

Como no ano anterior havia sido constatado que os alunos apenas reproduziam as montagens existentes nas revistas do kit LEGO ${ }^{\circledR}$ e considerando que, para Papert, reproduzir apenas não gera aprendizado - mas, somente quando o aluno é desafiado e deixado livre para pensar e explorar, apoiado em atividades que o ajudem - propôs-se um novo desafio aos alunos: produzir montagens novas, sem a utilização dos protocolos desse kit.

Assim, o aluno deverá estar constantemente interessado no aprimoramento de suas ideias e habilidades e solicitar do sistema educacional a criação de situações que permitem esse aprimoramento. Portanto, "deve ser ativo: sair da passividade de quem só recebe, para se tornar ativo. Neste momento os alunos foram deixados livres. Livres para buscar informações, selecioná-las, compreendê-las e relacioná-las, transformando-as em conhecimento.

Isso implica ser capaz de assumir responsabilidades, tomar decisões e buscar soluções para problemas complexos que não foram pensados anteriormente e que não podem ser atacados de forma fragmentada. Finalmente ele deve desenvolver habilidades, como ter autonomia, saber pensar, criar, aprender a aprender, de modo que possa continuar o aprimoramento de suas ideias e ações", no que é apresentado por Valente. (1999, p. 36). Durante o desenvolvimento de uma atividade como esta, o professor torna-se orientador, deixando de lado a ideia de que detém o conhecimento e apenas o repassa aos demais. Seu papel é de auxiliar o aluno na busca por respostas.
Para Castanha e Castro (2010), além dos elementos conceituais, este tipo de trabalho favorece a cooperação, a relação mais solidária com os seus pares e a conquista da descentração, tão necessárias para a superação do egocentrismo e imediatismo característicos desta geração.

O resultado do trabalho apresentado pelos alunos foi surpreendente, pois, depois de desafiados, os grupos responsáveis por desenvolverem os temas relacionados aos Sistemas Nervoso e Reprodutor criaram novas montagens, inexistentes, até o presente momento nas revistas do kit LEGO®.

O grupo que trabalhou com o Sistema Nervoso desenvolveu um robô que simula o arco reflexo. O robô, segundo o grupo, representa o nervo do osso patelar que fica localizado no joelho e que, quando é estimulado com um toque provoca uma reação conhecida como chute da perna.

Para esta construção (figura 1), o grupo utilizou peças de encaixe, um motor, lâmpadas led, conectores e o NXT. As peças de encaixe foram utilizadas para dar forma ao joelho e a medula espinal. Já as lâmpadas de led, quando acesas representavam as conexões entre neurônios sensitivos e motores, simbolizando o recebimento e interpretação da mensagem e gerando a ação do robô.

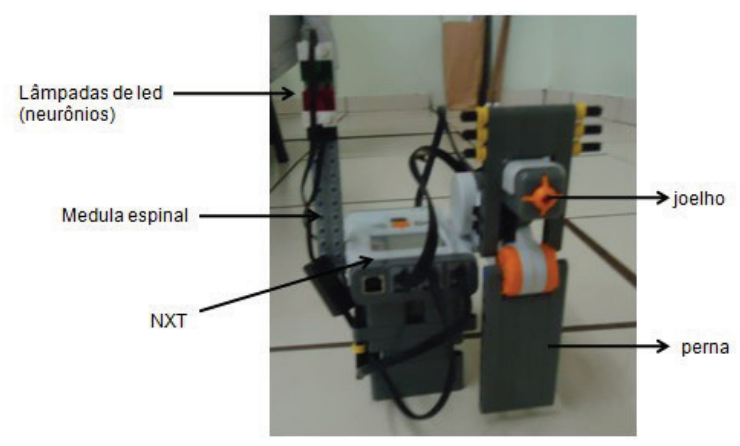

Figura 1 - Montagem do Robô Joelho

Como se pode observar, para montar o robô enfatizando todos estes aspectos descritos, a pesquisa bibliográfica para o desenvolvimento do referencial teórico foi imprescindível, pois serviu de base para entender o funcionamento das estruturas em questão, possibilitando ao aluno a construção e manipulação do concreto, do seu conhecimento de forma efetiva.

O grupo que desenvolveu o estudo sobre o Sistema Reprodutor, considerando o que interpretou sobre o processo de fecundação criou um Robô Espermatozoide (figura 2). O objetivo do Robô Espermatozoide é alcançar o óvulo, porém isto se torna impossível se ele encontrar um obstáculo, ou seja, o grupo aproveitou para demonstrar a barreira formada pelo uso da camisinha.

Com a montagem e a programação dos robôs pronta, os grupos realizaram testes para verificar se o funcionamento destes estava de acordo com o que haviam 


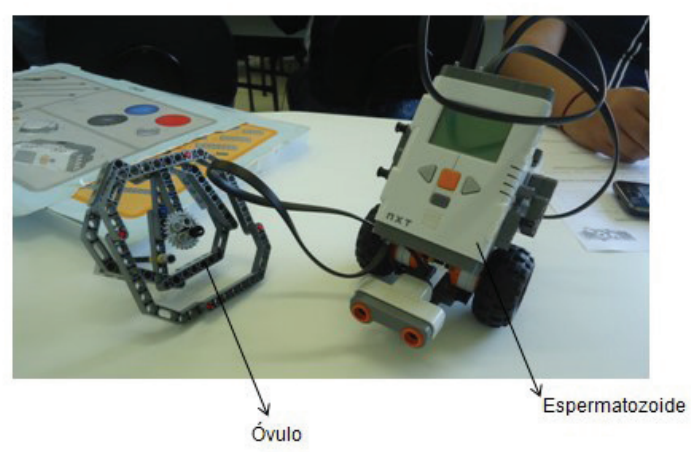

Figura 2 - Robô Espermatozoide e Óvulo

planejado. Quando os robôs não funcionavam como o esperado, foram realizados ajustes na programação, através do computador e do software de programação.

Por isso, é extremamente importante que o grupo, ou o aluno programador, realize a descrição da montagem, assim, caso ocorram problemas ele poderá voltar ao projeto para consulta, fazendo os devidos ajustes, pensando a programação e pensando para o robô.

\section{A mediação permanente do professor: A contribuição das TIC (Blog, Infográficos e Prezi).}

Quando se propõem aos alunos o trabalho com projetos de pesquisa, é importante destacar o papel do professor como orientador e não mais como detentor do saber. Ao longo do desenvolvimento do projeto é imprescindível que o professor tenha como acompanhar os alunos a fim de exercer este papel. Uma das formas encontradas para isso foi a construção de diários de bordo através de blogs. Com o diário de bordo o aluno pode planejar, registrar e divulgar a sua produção durante as aulas, sendo acompanhado pelo professor.

Mantovani (2005) descreve o blog como um tipo de publicação online que teve origem no hábito de algumas pessoas "logarem", ou seja, fazer anotações, transcrever, comentar os caminhos percorridos, tudo isso, conectado à web. É possível ainda, descrever o blog, conforme Boeira (2011), como um diário online que permite que os usuários registrem diversos conteúdos que ficam disponíveis em ordem cronológica, com a vantagem de que possibilita um espaço para comentários dos leitores.

Para construir um blog faz-se necessário escolher um site que ofereça o serviço de publicação. No caso deste trabalho, os alunos escolheram o Blogger, pois é oferecido pela Google. Para criar um blog usando o Blogger, basta ter uma conta Google através do Gmail, o que facilitou o uso do Blogger pelos alunos, tendo em vista que, nas primeiras aulas de informática os alunos abrem uma conta no Gmail e também porque os e-mails dos alunos, vinculados à escola, também são Gmail.

Considerando-o como um espaço de intercâmbio e colaboração, cada aluno criou o seu blog, disponibilizando o endereço para os demais colegas de turma e para as professoras. Desta forma, professores e colegas podem acompanhar o anda mento dos trabalhos. O blog toma a forma de um diário de bordo rico em textos descritivos, também importantes, pois através deles o aluno expressa o que trabalhou em aulas anteriores.

A elaboração dos diários de bordo através dos blogs permitiu que as professoras pudessem acompanhar o andamento do trabalho dos alunos dia a dia. Também foi possível fazer comentários, contribuindo assim, com as produções e exercendo o papel de orientador e, consequentemente, tornando-se mais próximo do aluno.

A construção dos blogs não serviu apenas para que as professoras acompanhassem o trabalho desenvolvido pelos grupos, mas também como fonte de pesquisa para a elaboração de outro recurso - os infográficos.

As imagens são recursos importantes no processo de aprendizagem. Utilizadas largamente na comunicação, hoje estão sendo incorporadas na educação. É cada vez mais habitual encontrá-las em livros didáticos, sites informativos, revistas, em geral.

Pode-se dizer que infográficos são representações visuais da informação, cujo objetivo é apresentá-la de forma mais dinâmica.

Para Módolo (2001, p.5), “atualmente a linguagem do infográfico, por dar preferência à imagem, parece encaixar-se mais adequadamente ao estilo de vida da população já que pode ser lido em poucos minutos", além de apresentar-se de uma forma fácil de compreender.

Considerando que o aluno da Geração dos Nativos Digitais (PRENSKY, 2010; VERAS, 2011) pensa graficamente ao invés de textualmente, a construção de infográficos também foi incluída no trabalho interdisciplinar. O desafio foi dado aos alunos para que construíssem infográficos sobre algumas doenças que acometem os sistemas estudados.

Para coletar as informações sobre as doenças, os grupos realizaram pesquisas bibliográficas através de livros didáticos e internet, tirando dúvidas com a professora de Ciências e, caso julgassem necessário, entrevistando especialistas.

Após a realização da pesquisa, foram orientados pela professora de Novas Tecnologias para o uso da ferramenta

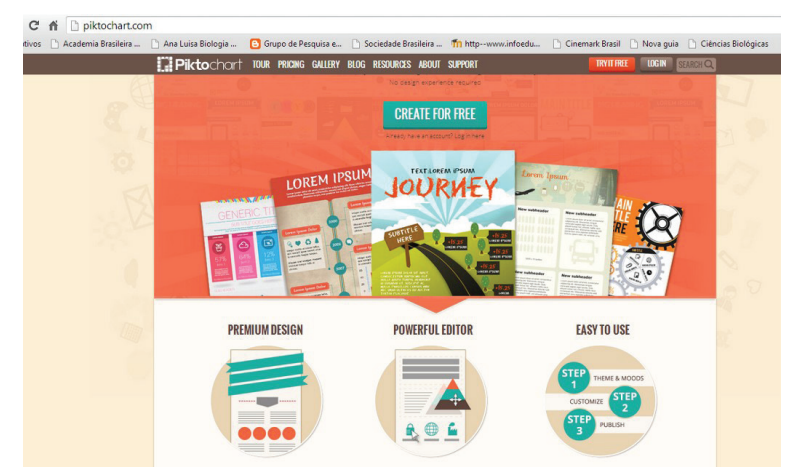

Figura 3 - Interface do PiktoChart 
PiktoChart (2013) (http://piktochart.com/), disponível gratuitamente na Internet, no site PiktoChart (figura 3).

O PiktoChart apresenta vários modelos de infográfico que podem ser personalizados, conforme o tema da sua pesquisa e a sua necessidade.

Cada infográfico foi criado levando em consideração a doença escolhida pelo grupo, dando ênfase para informações importantes e utilizando uma linguagem acessível.

O grupo que desenvolveu o trabalho sobre o Sistema Nervoso construiu um infográfico abordando o Mal de Parkinson (figura 4), evidenciando o que é a doença e quem são as pessoas que podem ser acometidas, além de algumas curiosidades.

Ao desenvolvê-lo, optou pelo uso de imagens e textos. As imagens remetem ao formato de um cérebro formado por engrenagens, relacionando o cérebro e a sua função como centro de controle das funções vitais.

Ao elaborarem infográficos os grupos exercitam a sua habilidade de síntese de conteúdo, transformando informações em conhecimento já que, para construí-lo é necessário pesquisar e selecionar as informações que serão utilizadas. Para selecionar as informações que o aluno considera mais importantes ele precisa dominar alguns aspectos relacionados aos temas desenvolvidos no trabalho e que serão utilizados para elaborar uma apresentação utilizando a ferramenta PREZI (2013).

É imprescindível destacar a importância da oralidade para o desenvolvimento da competência comunicativa

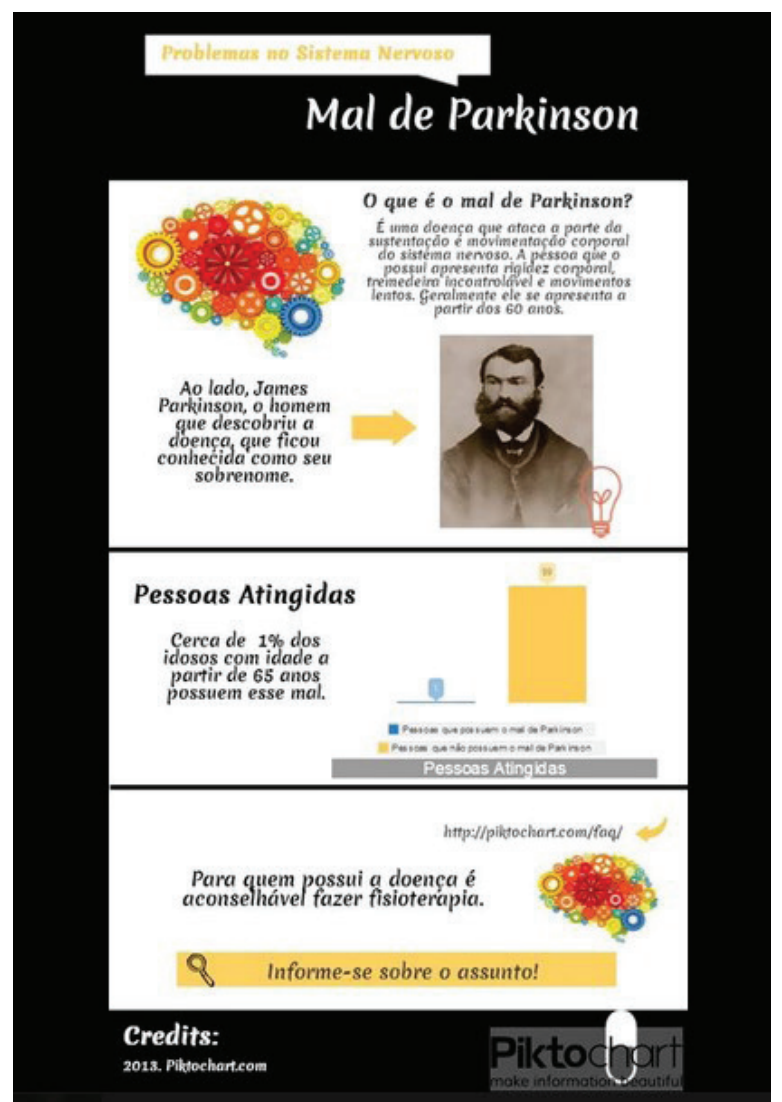

Figura 4 -Infográfico Representando o Sistema Nervoso do aluno. Assim, para concluir o trabalho desenvolvido, foi realizada uma socialização dos resultados para os professores, através de uma banca de apresentações utilizando como ferramenta auxiliar, o PREZI.

O Prezi é uma ferramenta inovadora para criar apresentações de impacto, na modalidade cloud, ou seja, disponibilizado na rede internet, gratuitamente, permitindo ao usuário um alto grau de liberdade na animação e na organização visual de seus conteúdos a serem apresentados, tornando-se um recurso intuitivo, fácil de utilizar e salvar seus trabalhos e que ainda permite a criação de apresentações não lineares, bem diferentes do padrão retangular com slides.

Para acessar a ferramenta, os alunos utilizaram os seus cadastros da rede social Facebook e computadores conectados à Internet. Cada nova conta possui uma galeria mostrando as exposições que foram criadas, com capacidade para armazenar suas novas criações, podendo ser compartilhados pelo sistema de nuvens.

Há modelos com imagens e ambientes tridimensionais, nos quais o autor cria textos podendo, durante a apresentação, dar ênfase ao conteúdo utilizando o zoom da tela. Também é possível carregar imagens e vídeos diretamente de sites. Prontas, as apresentações criadas podem ser disponibilizadas na nuvem, tornando- as ainda mais fáceis de serem compartilhadas e executadas.

O Prezi é uma ferramenta com boa aceitação pelos alunos devido a sua dinamicidade e interatividade. Acredita-se que, devido à facilidade com que os alunos utilizam-na, certamente irá substituir o Power Point nas apresentações de trabalhos.

Com todos os recursos utilizados e descritos até aqui, a seguir, apresenta-se a revista digital desenvolvida a partir do resultado do trabalho interdisciplinar dos alunos do $8^{\circ}$ ano, com o objetivo de integrar o material produzido e disponibilizar a experiência para outros professores e alunos.

\section{A culminância do projeto: desenvolvi- mento da Revista Digital}

Ao pensar a Revista Digital aqui apresentada, foram consideradas as ferramentas utilizadas pelos alunos para desenvolverem o trabalho interdisciplinar.

Tendo em vista que as ferramentas encontram-se disponíveis na Internet e são conhecidas também como recursos de Cloud Computing, ou computação nas nuvens. Para Alecrim (2013) esse modelo permite utilizar, em qualquer lugar e independente de plataforma, as mais variadas aplicações por meio da internet com a mesma facilidade de tê-las instaladas em nossos próprios computadores.

Sobre essa perspectiva buscou-se um ambiente que proporcionasse uma diversidade de formas de acesso, agradável e interativo ao público que poderá utilizar essa revista como objeto educacional. Assim, a ferramenta 
escolhida para desenvolvê-la foi o Flipboard.

O Flipboard é uma revista digital personalizada, onde o usuário, de uma maneira muito fácil e rápida consegue organizar as notícias de seu interesse alimentando-a automaticamente a partir das informações de Rede Sociais, ou através de blogs adicionados. É o jeito moderno de estar a par das notícias que interessam de forma personalizada.

Este aplicativo, ainda, tem um visual muito atrativo ao público (figura 5), uma vez que existe a possibilidade de se navegar entre as notícias como uma revista impressa, fazendo o mesmo movimento de folhear as páginas até então utilizado.

Uma das razões atribuídas a escolha deste aplicativo para a construção do ambiente foi devido o mesmo estar disponível para plataformas mobile como Android e iOS, além de poder ser acessada através da Internet. Desta forma o ambiente pode ser acessado de um tablet, de um celular, ou de um computador pessoal com acesso à Internet.

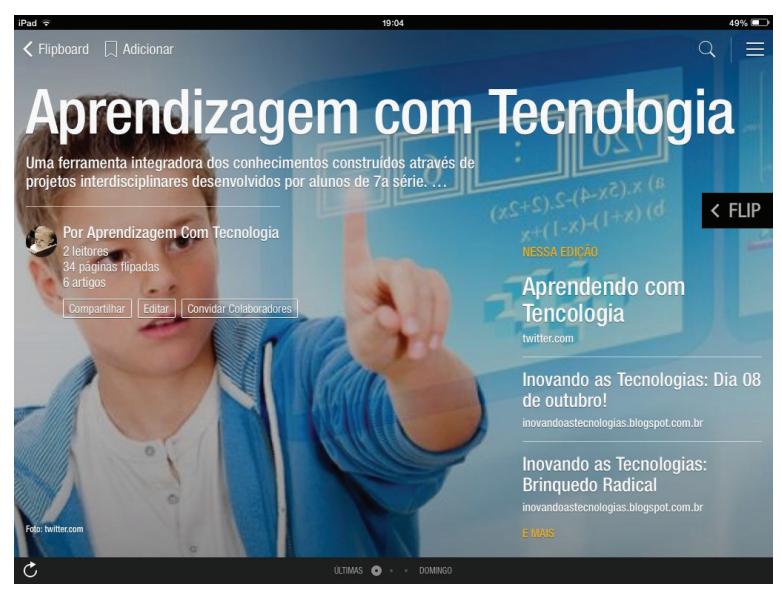

Figura 5 - Capa da Revista Digital

A alimentação dos artigos da revista dá-se de forma automática, onde, a partir do relacionamento de contas de redes sociais, ou endereços de blogs disponíveis na Internet, toda vez que o administrador das páginas relacionadas atualizá-las, a revista também ficará atualizada.

Como os alunos tem a prática de documentar suas atividades de Robótica e Novas Tecnologias em um blog particular, partiu-se para o relacionamento dos blogs dos alunos e de diversos outros meios de informação que estão dentro do mesmo contexto da problemática da pesquisa, como exemplo a conta no Twitter da LEGO Zoom, e outros vídeos disponíveis no Youtube, produzidos pelos alunos e professores. Ao final do processo é possível visualizar a revista montada automaticamente (figura 6) a partir da coleta de postagens dos blogs dos estudantes.

Com poucos cliques a revista é atualizada, seja através de um texto novo, de um blog de um estudante, ou de um vídeo postado no YouTube, ou ainda de alguma novidade da LEGO Zoom. Enfim, são várias as fontes

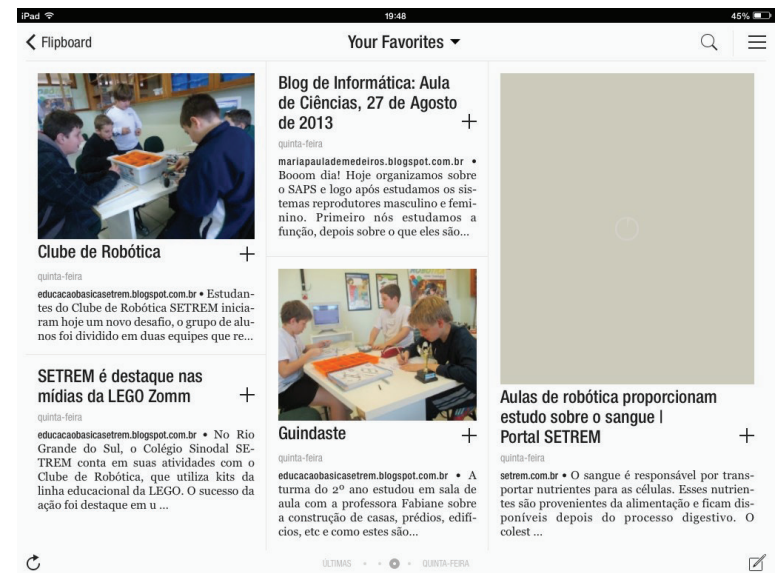

Figura 6 - Interior da Revista

utilizadas para proporcionar conteúdos atrativos aos estudantes e professores.

O acesso a Revista Digital Aprendizagem com Tecnologia pelos professores e estudantes é possível através de seus Tablets, Smartphones, ou pelo computador com acesso à Internet através do link ( http://flip.it/pBxf6 ).

Está acessível para alunos, professores e pessoas que queiram conhecer um pouco mais sobre o uso da tecnologia e da robótica para uma aprendizagem significativa, contribuindo para a construção do conhecimento.

Vale ressaltar que, todos os recursos utilizados para a criação da revista, incluindo o aplicativo Flipboard são gratuitos, ou seja, acessíveis a todos, sem custo.

\section{Considerações finais}

Nas escolas de Ensino Fundamental atuais predominam os alunos pertencentes à geração de nativos digitais que se caracteriza por estar cada vez mais conectada e aprender de uma forma diferente das gerações anteriores. Para essa geração, o uso das Tecnologias da Informação e Comunicação (TIC) se tornou indispensável no processo de aprendizagem.

A realização desse trabalho mostrou que a robótica educacional e o uso das TIC para o aprendizado de Ciências Naturais é possível e acessível, quando recursos como kits $\mathrm{LEGO}^{\circledR}$, computadores e internet estão disponíveis para os alunos, com o auxílio dos professores que atuam como orientadores no desenvolvimento dos trabalhos.

O emprego de tais ferramentas colaborou para o entendimento das diferentes formas de uso da robótica e do computador: quando é possível utilizá-lo na construção do conhecimento, sob uma perspectiva Construcionista (quando o aluno constrói algo a partir do que aprendeu) e não sendo apenas utilizado como fonte de informação, sob uma perspectiva Instrucionista.

Após o desenvolvimento do projeto, concluímos que os objetivos propostos foram atingidos, considerandose que o mesmo permitiu a criação de um ambiente 
integrador propício para o desenvolvimento de uma aprendizagem significativa e construção de conhecimentos substantivos em Ciências Naturais.

Espera-se que esses resultados possam contribuir para que mais professores possam buscar alternativas para a sua prática pedagógica, fazendo uso da robótica educacional e das TIC em sala de aula. Temos presente, no entanto, que para que isso ocorra, torna-se necessário a instrumentalização dos professores e a criação de espaços/ tempos para que este trabalho possa ser desenvolvido. Fato que pode ser considerado um fator limitante para o uso das TIC na construção do conhecimento.

\section{Referências}

ALECRIM, E. (2013). O que é Cloud Computing? Disponível em: www.infowester.com/ cloudcomputing. php>. Acesso em: 20 nov. 2013.

BOEIRA, A. F. (2011). Blogs na Educação: Blogando algumas possibilidades pedagógicas. Disponível em: $<$ http://tecnologiasnaeducacao.pro.br/revista/a1n1/ art10.pdf >. Acesso em: 15 jun. 2013.

CASTANHA, D.; CASTRO, M. B. de. (2010). A necessidade de refletir sobre as estratégias pedagógicas para atender à aprendizagem da Geração Y. Revista de Educação do Cogeime, v.19, n. 36, janeiro/junho. Disponível em: < www.redemetodista.edu.br/revistas/revistascogeime/ index.php/COGEIME/article/view/70/70>. Acesso em: 18 set. 2013.

AUTOR 1. (2014). Dissertação (Mestrado em Ensino Científico e Tecnológico). Santo Ângelo, Universidade Regional Integrada do Alto Uruguai e das Missões.

LEGO ZOOM EDUCATION. (2012). Trajetória de inovações e conquistas. Disponível em $<\mathrm{http}: / / \mathrm{www}$. legozoom.com/historia.aspx>. Acesso em 10 ago. 2012.

MANTOVANI, A. M. (2005). Weblogs na Educação: Construindo Novos Espaços de Autoria na Prática Pedagógica. Disponível em http://www.tise.cl/ archivos/tise2005/02.pdf. Acesso em: 15 out. 2013.

MÓDOLO, C. M. (2001). Infográficos: características, conceitos e princípios básicos. Intercom - Sociedade Brasileira de Estudos Interdisciplinares da Comunicação. XII Congresso Brasileiro de Ciências da Comunicação da Região Sudeste - Juiz de Fora MG, 2001. Disponível em: < http://www.ddiprojeto2. xpg.com.br/infograficos_caracteristicas_conceitos_e principios_basicos.pdf $>$. Acesso em: 25 out. 2013.

MORELATO, L. de A. (2010). et. al. Avaliando diferentes possibilidades de uso da Robótica na Educação.
Revista de Ensino de Ciências e Matemática, REnCiMa, v. 1, n. 2, p. 80-96, jul/dez. Disponível em: <http:// revistapos.cruzeirodosul.edu.br/index.php/rencima/ article/view/11>. Acesso em: 19 set. 2013.

PAPERT, S. (2008). A máquina das crianças: repensando a escola na era da informática. Porto Alegre: Artmed, 2008.

PIKTOCHART. (2013). Disponível em: <http://piktochart. com/>. Acesso em: 21 jun. 2013.

PRENSKY, M. (2010). Não me atrapalhe, mãe: eu estou aprendendo. São Paulo: Phorte.

PREZI. (2013). Disponível em: <https://prezi.com>. Acesso em: 21 jun. 2013.

QUINTANILHA, L. (2008). Irresistível robô. Disponível em $<$ http://www.arede.inf.br/index.php?option=com content\&task $=$ view\&id=1344\&Itemid=99>. Acesso em: 18 jun. 2012.

VALENTE, J. A. (1999). Por quê o computador na educação? Disponível em: <http://www.ich.pucminas. br/pged/db/wq/wq1_LE/local/txtie9doc.pdf $>$ Acesso em: 27 set. 2013.

VERAS, M. (org). (2011). Inovação e Métodos de Ensino para nativos Digitais. São Paulo: Atlas. 